\title{
Single-Stranded Conformational Polymorphism
}

National Cancer Institute

\section{Source}

National Cancer Institute. Single-Stranded Conformational Polymorphism. NCI

Thesaurus. Code C17762.

A Single-Stranded Conformational Polymorphism consists of nucleotide sequence variation in the same region of DNA between individuals within a species, or between alleles in an individual, that cause partially denatured DNA fragments to take on different conformations as a result of their nucleotide sequences differences. These conformation differences can be detected through various gel-separation techniques. 